\title{
Experimental study of epidermal growth factor and acidic fibroblast growth factor in the treatment of diabetic foot wounds
}

\author{
JIASHENG XU ${ }^{1,2}$, DINGHONG MIN ${ }^{1}$, GUANGHUA GUO ${ }^{1}$, XINCHENG LIAO ${ }^{1}$ and ZHONGHUA FU ${ }^{1}$ \\ ${ }^{1}$ Burn Center, The First Affiliated Hospital of Nanchang University; \\ ${ }^{2}$ Graduate School of Nanchang University, Nanchang, Jiangxi 330001, P.R. China
}

Received October 21, 2017; Accepted January 21, 2018

DOI: $10.3892 /$ etm.2018.6131

\begin{abstract}
The aim of the present study was to investigate the effect of epidermal growth factor (EGF) and acidic fibroblast growth factor (aFGF) on the healing of diabetic foot wounds. A total of 199 patients with diabetic foot ulcers were recruited and randomly divided into four groups: A recombinant human EGF group ( $\mathrm{n}=50)$, an aFGF group $(\mathrm{n}=50)$, a combined EGF and aFGF group $(\mathrm{n}=50)$ and a normal saline control group $(n=49)$. Patients in all groups received a daily dressing change and growth factor reagents were applied topically when dressing. To observe the time required for each stage of wound healing, the epidermal healing rate and granulation tissue growth were recorded. Following 3-4 days of treatment, the wound healing stage was similar in all groups. Later stages (following 4 days) of wound healing were achieved significantly faster in the combined group compared with the control group $(\mathrm{P}<0.05)$. The rate of wound healing in the EGF group was similar to that observed in the combination group. No significant difference was observed between the EGF and aFGF groups during the initial period of wound healing. However, in the later stage (following 4 days), the combined use of recombinant human EGF and aFGF had a marked positive effect on wound healing when compared with the control group. Growth factors have extensive biological activities with functions including promoting cell proliferation as well as rehabilitating and regenerating tissues, which serve important roles in wound healing.
\end{abstract}

\section{Introduction}

Diabetic foot wounds are a complication of diabetic peripheral neuropathy and manifest as peripheral vascular lesions in the lower limbs of patients with diabetes mellitus (1). Lesions may

Correspondence to: Dr Zhonghua Fu, Burn Center, The First Affiliated Hospital of Nanchang University, 17 YongWaiZheng Street, East Lake, Nanchang, Jiangxi 330001, P.R. China E-mail: fzh0625@163.com

Key words: diabetic foot wound, epidermal growth factor acidic fibroblast growth factor, wound healing lead to lower limb infection, ulcer formation and the destruction of deep tissue (2). Diabetic foot wounds are prone to relapse and wound healing is extremely slow; as such, clinical treatments typically have poor outcomes, which may cause long-term physical and mental suffering and financial hardship for the patient (3). It has previously been demonstrated that reduced absolute or relative levels of growth factors may contribute to healing resistance in diabetic foot wounds (4). The majority of research has focused on mechanisms underlying the involvement of growth factors in diabetic foot wound healing, whereas few clinic trials have been performed to assess the efficacy of growth factor treatments on diabetic foot wound healing (5). More rigorous and accurate randomized controlled trials are required to investigate the clinical efficacy of growth factors.

The clinical use of recombinant human epidermal growth factor (EGF) and fibroblast growth factor (FGF) is common (6). However, comparative studies of the treatment effects of these growth factors alone or combined are few. The aim of the present study was to investigate the effects of EGF and acidic FGF (aFGF) factors on diabetic foot wound healing, alone and in combination.

\section{Materials and methods}

Patients. A total of 199 patients with diabetic foot ulcers were recruited at the Burn Treatment Center of the First Affiliated Hospital of Nanchang University (Nanchang, China) between February 2015 and February 2017. All patients volunteered to participate in the present study and provided written informed consent. The present study has been approved by the Ethics Committee of the First Affiliated Hospital of Nanchang University. Patient demographics are presented in Table I.

All patients met the following inclusion criteria: Type II diabetes mellitus according to the World Health Organization diagnostic criteria (7), wounds of grade II according to the Wagner grading method (8) and wounds located in the foot with good blood supply (or located at the toe with limb salvage treatment required). The nutritional status of enrolled patients was good (malnourished patients were given underlying nutritional support before treatment). The exclusion criteria were as follows: Presence of other serious complications, other serious diseases, foot gangrene or severe ischemic necrosis where amputation treatment was required. 
Treatment groups. Patients were randomly divided into four groups: A combination treatment group (EGF + aFGF; $n=50)$, a recombinant human EGF group $(n=50)$, an aFGF group $(n=50)$ and a normal saline control group $(n=49)$. The fasting blood glucose levels of all patients were $<11.1 \mathrm{mmol} / 1$ prior to wound treatment. Antibiotics (cftazidime, administered via $1 \mathrm{~g} / 12 \mathrm{~h}$ intravenous drip) were used to completely control the infection. Antibiotics were used in all patients at the same dosage for 3-7 days according to severity and were not used in the trial following the administration of growth factor reagents (beginning 3 days following the cessation of antibiotic treatment). Therefore, antibiotics should not influence the results of the present study. Debridement, cleaning and pathological granulation removal were performed prior to the start of this experimental study. EGF was provided by Shenzhen Watsin Genetech Co., Ltd. (Shenzhen, China) and aFGF was provided by Shanghai Tenry Pharmaceutical Co., Ltd. (Shanghai, China).

Treatment methods. Patients were administered with growth factors according to the manufacturer's recommended dosage. Patients in the combination treatment group were treated with topical recombinant human EGF at $40 \mathrm{IU} / \mathrm{cm}^{2}$ and $\mathrm{aFGF}$ at $40 \mathrm{AU} / \mathrm{cm}^{2}$. Patients in the recombinant human EGF treatment group were treated with topical recombinant human EGF at $40 \mathrm{IU} / \mathrm{cm}^{2}$. Patients in the aFGF group were treated with topical aFGF $40 \mathrm{AU} / \mathrm{cm}^{2}$. For patients in the control group, the wound was cleaned with normal saline only. Growth factors were dissolved in normal saline and applied evenly to the surface of the lesions prior to dressing application. Dressings were changed and treatments were applied once per day for a total of 60 days.

Observation indices. The time required for wound healing at each stage was recorded. The healing stage was determined by the percentage of the wound healed and the degree of granulated tissue growth. Wound healing percentage $=[$ (initial wound area-corresponding time-point wound area)/initial wound area] $\mathrm{x} 100$. To assess the degree of granulation, the following scoring system was used: No new granulated tissue formation in the wound surface, grade 0 . New granulated tissue formation in the wound surface, grade 1. Granulated tissue accounting for $50 \%$ of the total wound area, grade 2 . Granulated tissue covering the entire wound area, grade 3 . The time taken to reach granulation grade 1,2 and 3 in each group was recorded for each patient. The time taken to reach 50 and $100 \%$ healing were also recorded.

Statistical analysis. SPSS v18.0 (SPSS, Inc., Chicago, IL, USA) were used for statistical analysis. Data were analyzed by two-way analysis of variance followed by a post-hoc Student-Newman-Keuls q-test. Data are presented as the mean \pm standard deviation. $\mathrm{P}<0.05$ was considered to indicate a statistically significant difference.

\section{Results}

Patient demographics. According to the diagnostic criteria, 199 patients with diabetic foot wounds classified as Wagner grade II were enrolled in the present study. No patients withdrew or were lost to follow-up and all are included in the analysis. No significant differences were observed in diabetes mellitus history, age, original wound surface area and duration of wound formation between any of the groups (Table I).

Wound healing. Wound healing initiation was observed in all groups within 4 days of the start of treatment and no significant difference was observed between groups (Fig. 1 and Table II). However, 50\% wound healing and complete wound healing were achieved with significantly shorter treatment durations in the combination group compared with the control group $(\mathrm{P}<0.01$; Fig. 1 and Table II). Similar results were observed in the EGF treatment group, with significantly shorter $50 \%$ and complete wound healing durations compared with the control group ( $\mathrm{P}<0.05$; Fig. 1 and Table II).

Granulated tissue maturation. No significant difference in the duration of treatment required to achieve granulated tissue growth grade 1was observed between groups (Table III). However, granulated tissue growth grades 2 and 3 were achieved with a significantly shorter treatment time in the combination $(\mathrm{P}<0.01)$ and EGF $(\mathrm{P}<0.05)$ groups compared with the control (Table III). No significant differences in treatment time were observed between the aFGF and control groups for any granulated tissue grade.

\section{Discussion}

Diabetic foot wounds represent a refractory disease that may be caused by multiple factors and the associated pathophysiological processes are very complex. Diabetic foot refers to pathological changes caused by chronic diabetes mellitus (9) and typically manifests as pathological changes to blood vessels and nerves in the lower limbs (10). Infection of ulcers is common and foot gangrene is the most serious complication associated with diabetic foot (11-13). It is thought that decreased levels of growth factors and their receptors in the diabetic foot result in wounds that are resistant to healing (14). However, previous animal studies have reported that growth factor therapy does not aid diabetic wound healing in mice (15-18). Some studies have suggested that decreased local growth factor activity, including growth factor glycosylation, is responsible for delayed wound healing (19-21).

In the present study, wounds had begun to heal in all groups following 3-4 days of treatment. However, as treatment continued, healing was significantly faster in the EGF and combination groups compared with the normal control. The time taken for granulated tissue to reach Wagner grade 1 was also similar in all groups, whereas grades 2 and 3 were achieved significantly faster in the EGF and combination groups compared with the control. In order to interpret these results, the mechanism by which growth factors promote wound healing must be investigated.

The accumulation of necrotic tissue, severe inflammation and a decrease in EGF release in a wound results in local increases in sugar levels, non-enzymatic glycosylation and advanced glycation end products (AGEs) (22). The increase in AGEs negatively regulates cell proliferation, inflammatory reactions and granulated tissue maturation (23), thereby inhibiting the function of fibroblasts, vascular endothelial 
Table I. Basic information comparison of the four included groups.

\begin{tabular}{lccccccc}
\hline Group & $\begin{array}{c}\text { Case } \\
\text { number }\end{array}$ & $\begin{array}{c}\text { Diabetes mellitus } \\
\text { history (year) }\end{array}$ & Age & $\begin{array}{c}\text { Wound } \\
\text { area/cm }\end{array}$ & $\begin{array}{c}\text { Wound formation } \\
\text { Time/week }\end{array}$ & Male & Female \\
\hline $\begin{array}{l}\text { Combination group of } \\
\text { the growth factors }\end{array}$ & 50 & $12.67 \pm 3.96$ & $61 \pm 5.31$ & $3.6 \pm 0.5$ & $12 \pm 0.53$ & 26 & 24 \\
$\begin{array}{l}\text { Human epidermal } \\
\text { growth factor group }\end{array}$ & 50 & $13 \pm 4.88$ & $65 \pm 3.65$ & $4.7 \pm 0.3$ & $16 \pm 0.62$ & 25 & 25 \\
$\begin{array}{l}\text { Acidic fibroblast } \\
\text { growth factor group }\end{array}$ & 50 & $15 \pm 6.72$ & $60 \pm 6.21$ & $5.1 \pm 0.2$ & $14 \pm 0.27$ & 24 & 26 \\
$\begin{array}{l}\text { Control group } \\
\begin{array}{l}\text { P-value } \\
\hline\end{array}\end{array}$ & 49 & $12 \pm 4.26$ & $63 \pm 4.56$ & $4.2 \pm 0.4$ & $13 \pm 0.35$ & 25 & 24 \\
\hline
\end{tabular}

Statistic analysis the diabetes mellitus history, age, size of original wound surface, time of wound formation demonstrate no statistic significant between those four groups $(\mathrm{P}>0.05)$.
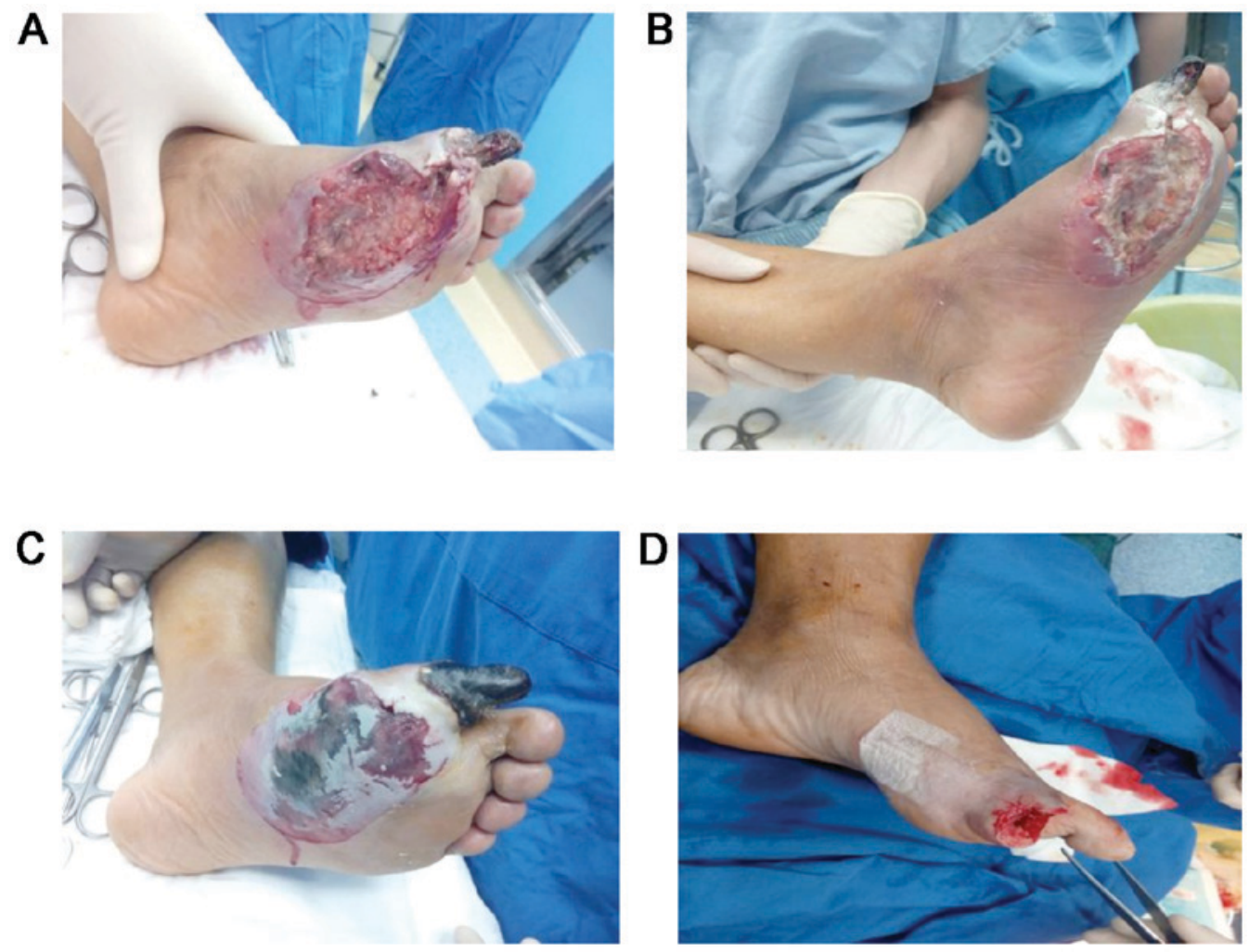

Figure 1. Representative images of a patient with a diabetic foot wound at different treatment stages. Image of wound (A) prior to treatment, (B) at wound healing initiation stage, (C) at 50\% wound surface healing stage and (D) at complete wound healing stage.

cells and epidermal stem cells to delay wound healing. Several large-sample randomized double-blind studies have been performed to assess the effect of EGF treatment in diabetic foot ulcers (14-17,24-27) and it has previously been reported that the application of exogenous EGF has a good curative effect in diabetic wounds (28).

Under normal physiological conditions, FGF binds to a tyrosine kinase receptor, leading to signal transduction (29) to stimulated fibroblasts and vascular endothelial cells to move towards the site of trauma (30). FGF and AGEs have the same receptor binding sites, and so when the concentration of AGEs is elevated (31) the function of FGF is inhibited. Conversely, when local FGF is applied, the increase of exogenous FGF (32) inhibits the binding of AGEs to the tyrosine kinase receptor and accelerates wound healing. A previous controlled trial treated diabetic foot wounds with FGF alone (31) and the results demonstrated that the use of exogenous FGF effectively promoted wound healing (33).

Few studies have been performed to investigate the effect of combined EGF and aFGF on diabetic foot wounds (32). Based on the mechanism by which growth factors promote wound repair, the difficult healing of clinical diabetic foot 
Table II. Treatment duration and for wound healing.

\begin{tabular}{lccc}
\hline Group & $\begin{array}{c}\text { Wound healing initiation } \\
\text { time (days) }\end{array}$ & $\begin{array}{c}50 \% \text { wound surface healing } \\
\text { time (days) }\end{array}$ & $\begin{array}{c}\text { Complete wound healing } \\
\text { time (days) }\end{array}$ \\
\hline aFGF + EGF & $3.3 \pm 0.60$ & $17.21 \pm 0.36^{\mathrm{b}}$ & $36.31 \pm 1.62^{\mathrm{b}}$ \\
EGF & $3.4 \pm 0.82$ & $19.35 \pm 0.76^{\mathrm{a}}$ & $38.51 \pm 1.46^{\mathrm{a}}$ \\
aFGF & $3.5 \pm 0.78$ & $22.42 \pm 0.86$ & $41.83 \pm 1.78$ \\
Normal control & $3.5 \pm 0.56$ & $25.36 \pm 0.48$ & $47.52 \pm 1.82$ \\
\hline
\end{tabular}

${ }^{\mathrm{a}} \mathrm{P}<0.05$ and ${ }^{\mathrm{b}} \mathrm{P}<0.01$ vs. control group. aFGF, acidic fibroblast growth factor; EGF, epidermal growth factor.

Table III. Treatment duration and granulated tissue growth.

\begin{tabular}{lllr}
\hline & & \multicolumn{2}{c}{ Treatment duration for granulated tissue growth (days) } \\
\cline { 2 - 4 } Group & Grade 1 & Grade 2 & Grade 3 \\
\hline aFGF + EGF & $3.61 \pm 0.72$ & $10.23 \pm 0.57^{\mathrm{b}}$ & $26.19 \pm 1.35^{\mathrm{b}}$ \\
EGF & $3.83 \pm 0.63$ & $11.65 \pm 0.71^{\mathrm{a}}$ & $28.31 \pm 1.68^{\mathrm{a}}$ \\
aFGF & $4.12 \pm 0.78$ & $13.73 \pm 0.69$ & $31.07 \pm 1.03$ \\
Normal control & $3.94 \pm 0.22$ & $16.27 \pm 0.61$ & $37.21 \pm 1.27$ \\
\hline
\end{tabular}

${ }^{\mathrm{a}} \mathrm{P}<0.05$ and ${ }^{\mathrm{b}} \mathrm{P}<0.01$ vs. control group. aFGF, acidic fibroblast growth factor; EGF, epidermal growth factor.

wounds can be explained by the following aspects: The function of local microenvironment is changed such as strong inflammatory response, necrotic tissues, and enhanced glycosylation. Changes in the local microenvironment inhibit the function of fibroblasts, endothelial cells and epidermal cells in wound repair (34). When exogenous growth factors are applied to necrotic tissue, the high level of local AGEs results in competitive inhibition at the early stage of wound healing, countering the curative effect of the growth factors (35). In the later stages of would healing, a sufficient amount of exogenous growth factors will have entered the necrotic tissue, significantly increasing the local growth factor concentration and outcompeting AGEs for binding sites. As such, the effect of exogenous growth factors on wound healing is more obvious with increased treatment time. Combined use of EGF and aFGF results in a more rapid increase in local growth factor concentration, accelerating the binding site competition process and ultimately promoting cell proliferation. Combination treatment may promote mitosis, signal transduction, endogenous growth factor production and inflammatory cell chemotaxis of fibroblasts. These processes all contribute to accelerating the healing rate of the tissue (36).

The differences between EGF and aFGF treatment remain unclear and a larger clinical investigation is required. However, based on the present study it may be hypothesized that EGF treatment is more effective than aFGF for treating diabetic foot wounds. A possible reason for this difference is that diabetic foot wound tissues release low levels of EGF and using exogenous growth factors directly increases the concentration of EGF in the wound, which may have a negative feedback effect on non-enzymatic glycosylation to directly accelerate the process of tissue repair. aFGF, on the other hand, is a competitive antagonist of AGEs and therefore a high local concentration is required to improve wound healing. As such, a longer treatment time is required to observe the curative effects of aFGF compared with EGF (37-39).

It has previously been reported that epidermis cell proliferation is associated with age (40). Tiaka et al (35) suggested that diabetes, medical history, age and foot blood perfusion may influence wound healing. At the start of the present study, the baseline data of patients in each group were compared and no significant differences were observed. During treatment, patients were prescribed bed rest in order to prevent differences in the load applied to the wounded foot. The results of the present study demonstrate that growth factors have good biological activity in that they promote the growth of granulation tissue and that in combination with EGF and aFGF treatment, they are important for angiogenesis and wound repair. However, there were several limitations to the present study. The results suggest that the combination of two growth factors promotes wound healing, but the relationship between dosage and healing effect was not investigated. Furthermore, a small sample size was used and it could not be determined whether individual factors, including sex, may affect the results. The molecular mechanism by which growth factors promote wound healing remains unclear and further research is required to explore relevant signaling pathways and determine which factors influence the efficacy of growth factor treatment.

In summary, the present study assessed the clinical effect of growth factors as a treatment for diabetic foot wounds. The results indicated that combined application of EGF and aFGF effectively promotes wound healing. Diabetic foot wound 
healing involves several pathological processes and so the treatment regime used in the present study may need to be further improved. It could be optimized based on further study of the pathogenesis of the disease, as well as further evaluation of pharmacological agents, treatment duration, dosage and route of administration (41). Using a combination of multiple growth factors and dosages at different stages may improve the therapeutic efficacy of growth factor treatment in diabetic foot wound. Further studies are required to validate these findings.

\section{Acknowledgements}

The authors would like to thank Ms. Liao Kaili for her support and encouragement.

\section{Funding}

No funding was received.

\section{Availability of data and materials}

The analyzed data sets generated during the present study are available from the corresponding author on reasonable request.

\section{Authors' contributions}

JX designed the direction of research and implemented it, collected clinical data and statistical analysis and wrote the manuscript. DM collected clinical data and dressing changes. GG conducted quality assessments and performed result analysis. XL dressed and collected clinical data. ZF reviewed and revised the manuscript and aided in communication for publication.

\section{Ethics approval and consent to participate}

The present study was approved by the ethics committee of the First Affiliated Hospital of Nanchang University and written informed consent was obtained from all patients.

\section{Consent for publication}

Not applicable.

\section{Competing interests}

The authors declare that they have no competing interests.

\section{References}

1. Everett $\mathrm{E}$ and Mathioudakis N: Update on management of diabetic foot ulcers. Ann NY Acad Sci 1411: 153-165, 2018

2. Babaei V, Afradi H, Gohardani HZ, Nasseri F, Azarafza M and Teimourian S: Management of chronic diabetic foot ulcers using platelet-rich plasma. J Wound Care 26: 784-787, 2017.

3. Dinh T, Tecilazich F, Kafanas A, Doupis J, Gnardellis C, Leal E, Tellechea A, Pradhan L, Lyons TE, Giurini JM and Veves A: Mechanisms involved in the development and healing of diabetic foot ulceration. Diabetes 61: 2937-2947, 2012.

4. Demidova-Rice TN, Hamblin MR and Herman IM: Acute and impaired wound healing: Pathophysiology and current methods for drug delivery, part 2: Role of growth factors in normal and pathological wound healing: Therapeutic potential and methods of delivery. Adv Skin Wound Care 25: 349-370, 2012.
5. Sridharan K and Sivaramakrishnan G: Growth factors for diabetic foot ulcers: Mixed treatment comparison analysis of randomized clinical trials. Br J Clin Pharmacol 84: 434-444, 2017.

6. Laiva AL, O'Brien FJ and Keogh MB: Innovations in gene and growth factor delivery systems for diabetic wound healing. J Tissue Eng Regen Med: May 8, 2017 (Epub ahead of print).

7. Stern MP, Valdez RA, Haffner SM, Mitchell BD and Hazuda HP: Stability over time of modern diagnostic criteria for type II diabetes. Diabetes Care 16: 978-983, 1993.

8. Wagner FW: Transcutaneous Doppler ultrasound in the prediction of healing and the selection of surgical level for dysvascular lesions of the toes and forefoot. Clin Orthop Relat Res 142: 110-114, 1979.

9. Al-Rubeaan K, Al Derwish M, Ouizi S, Youssef AM, Subhani SN, Ibrahim HM and Alamri BN: Diabetic foot complications and their risk factors from a large retrospective cohort study. PLoS One 10: e0124446, 2015.

10. Naz I, Walters E, Akbari CM, Attinger CE and Kim PJ: Noninvasive vascular assessment of lower extremity wounds in diabetics: Are we able to predict perfusion deficits? Surg Technol Int 31: 66-74, 2017.

11. Gope ML and Gope R: Tyrosine phosphorylation of EGF-R and PDGF-R proteins during acute cutaneous wound healing process in mice. Wound Repair Regen 17: 71-79, 2009.

12. Pastore S, Mascia F, Mariani V and Girolomoni G: The epidermal growth factor receptor system in skin repair and inflammation. J Invest Dermatol 128: 1365-1374, 2008.

13. Schumacher B, Pecher P, Von Specht BU and Stegmann T: Induction of neoangiogenesis in ischemic myocardium by human growth factors: First clinical results of a new treatment of coronary heart disease. Circulation 97: 645-650, 1998.

14. Simons M, Annex BH, Laham RJ, Kleiman N, Henry T, Dauerman H, Udelson JE, Gervino EV, Pike M, Whitehouse MJ, et al: Pharmacological treatment of coronary artery disease with recombinant fibroblast growth factor-2: Double-blind, randomized, controlled clinical trial. Circulation 105: 788-793, 2012.

15. Eppler SM, Combs DL, Henry TD, Lopez JJ, Ellis SG, Yi JH, Annex BH, Mccluskey ER and Zioncheck TF: A target-mediated model to describe the pharmacokinetics and hemodynamic effects of recombinant human vascular endothelial growth factor in humans. Clin Pharmacol Ther 72: 20-32, 2013.

16. Richardson TP, Peters MC, Ennett AB and Mooney DJ: Polymeric system for dual growth factor delivery. Nat Biotechnol 19: 1029-1034, 2001.

17. Chen RR, Silva EA, Yuen WW, Brock AA, Fischbach C, Lin AS, Guldberg RE and Mooney DJ: Integrated approach to designing growth factor delivery systems. FASEB J 21: 3896-3903, 2007.

18. Marui A, Kanematsu A, Yamahara K, Doi K, Kushibiki T, Yamamoto M, Itoh H, Ikeda T, Tabata Y and Komeda M: Simultaneous application of basic fibroblast growth factor and hepatocyte growth factor to enhance the blood vessels formation. J Vasc Surg 41: 82-90, 2015.

19. Ghiasi Z, Gray T, Tran P, Dubielzig R, Murphy C, McCartney DL and Reid TW: The effect of topical Substance-P plus insulin-like growth factor-1 (IGF-1) on epithelial healing after photorefractive keratectomy in rabbits. Transl Vis Sci Technol 7: 12, 2018.

20. An Y, Liu WJ, Xue P, Ma Y, Zhang LQ, Zhu B, Qi M, Li LY, Zhang YJ, Wang QT and Jin Y: Autophagy promotes MSC-mediated vascularization in cutaneous wound healing via regulation of VEGF secretion. Cell Death Dis 9: 58, 2018.

21. Saijo H, Kilpadi DV and Akita S: Evaluation of the use of recombinant human basic fibroblast growth factor in combination with negative pressure wound therapy with instillation and dwell time in porcine full-thickness wound model. Wound Repair Regen: Jan 12, 2018 (Epub ahead of print).

22. Simmons CA, Alsberg E, Hsiong S, Kim WJ and Mooney DJ: Dual growth factor delivery and controlled scaffold degradation enhance in vivo bone formation by transplanted bone marrow stromal cells. Bone 35: 562-569, 2004.

23. Basmanav FB, Kose GT and Hasirci V: Sequential growth factor delivery from complexed microspheres for bone tissue engineering. Biomaterials 29: 4195-4204, 2008.

24. Patel ZS, Young S, Tabata Y, Jansen JA, Wong ME and Mikos AG: Dual delivery of an angiogenic and an osteogenic growth factor for bone regeneration in a critical size defect model. Bone 43: 931-940, 2008 . 
25. Hutchings $\mathrm{H}$, Ortega $\mathrm{N}$ and Plouet J: Extracellular matrix-bound vascular endothelial growth factor promotes endothelial cell adhesion, migration, and survival through integrin ligation. FASEB J 17: 1520-1522, 2013.

26. Tsou R and Isik FF: Integrin activation is required for VEGF and FGF receptor protein presence on human microvascular endothelial cells. Mol Cell Biochem 224: 81-89, 2011.

27. Li B, Davidson JM and Guelcher SA: The effect of the local delivery of platelet-derived growth factor from reactive two-component polyurethane scaffolds on the healing in rat skin excisional wounds. Biomaterials 30: 3486-3494, 2009.

28. Silva AK, Richard C, Bessodes M, Scherman D and Merten OW: Growth factor delivery approaches in hydrogels. Biomacromolecules 10: 9-18, 2009.

29. Sakiyama-Elbert SE and Hubbell JA: Development of fibrin derivatives for controlled release of heparin-binding growth factors. J Control Release 65: 389-402, 2000.

30. Zhang X, Ding X, Lin X, Yang P and Lin K: Clinical observation of recombinant human epidermal growth factor combined with lipoic acid in the treatment of diabetic foot. Chin Pharm 27: 4147-4149, 2016 (In Chinese).

31. Johnson NR and Wang Y: Controlled delivery of heparin-binding EGF-like growth factor yields fast and comprehensive wound healing. J Control Release 166: 124-129, 2013.

32. Bae IH, Park JW and Kim DY: Enhanced regenerative healing efficacy of a highly skin-permeable growth factor nanocomplex in a full-thickness excisional mouse wound model. Int J Nanomedicine 9: 4551-4567, 2014.

33. Loot MA, Kenter SB, Au FL, van Galen WJ, Middelkoop E, Bos JD and Mekkes JR: Fibroblasts derived from chronic diabetic ulcers differ in their response to stimulation with EGF, IGF-I, bFGF and PDGF-AB compared to controls. Eur J Cell Biol 81: $153-160,2002$.
34. Nie K, Li P, Zeng X, Sun G, Jin W, Wei Z, Wang B, Qi J, Wang $Y$ and Wang D: Clinical observation of basic fibroblast growth factor combined with topical oxygen therapy in enhancing burn wound healing. Chin J Rep Rec Surg 6: 643-646, 2010 (In Chinese).

35. Tiaka EK, Papanas N, Manolakis AC and Maltezos E: The role of nerve growth factor in the prophylaxis and treatment of diabetic foot ulcers. Int J Burns Trauma 1: 68-76, 2011.

36. Sheridan MH, Shea LD, Peters MC and Mooney DJ: Bioabsorbable polymer scaffolds for tissue engineering capable of sustained growth factor delivery. J Control Release 64: 91-102, 2000.

37. Chen RR and Mooney DJ: Polymeric growth factor delivery strategies for tissue engineering. Pharm Res 20: 1103-1112, 2003.

38. Zhu $\mathrm{XH}$, Wang $\mathrm{CH}$ and Tong YW: In vitro characterization of hepatocyte growth factor release from PHBV/PLGA microsphere scaffold. J Biomed Mater Res A 89: 411-423, 2009.

39. Pepper MS, Ferrara N, Orci L and Montesano R: Potent synergism between vascular endothelial growth factor and basic fibroblast growth factor in the induction of angiogenesis in vitro. Biochem Biophys Res Commun 189: 824-831, 1992.

40. Jimenez Hamann MC, Tator CH and Shoichet MS: Injectable intrathecal delivery system for localized administration of EGF and FGF-2 to the injured rat spinal cord. Exp Neurol 194: 106-119, 2005.

41. Yang HS, Shin J, Bhang SH, Shin JY, Park J, Im GI, Kim CS and Kim BS: Enhanced skin wound healing by a sustained release of growth factors contained in platelet-rich plasma. Exp Mol Med 43: 622-629, 2011 